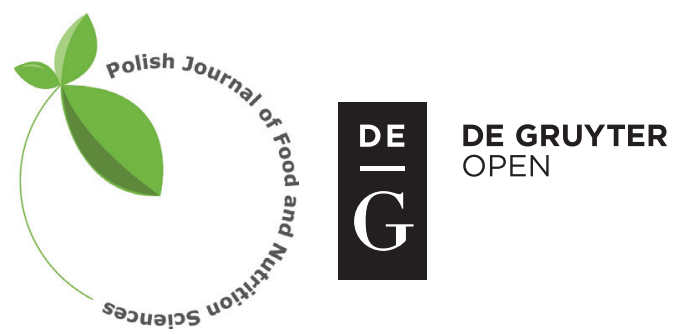

Pol. J. Food Nutr. Sci., 2016, Vol. 66, No. 4, pp. 295-302

DOI: $10.1515 /$ pjfns-2015-0054 http://journal.pan.olsztyn.pl

Original article

Section: Food Quality and Functionality

\title{
Evaluation of Chitosan/Fructose Model as an Antioxidant and Antimicrobial Agent for Shelf Life Extension of Beef Meat During Freezing
}

\author{
Mohmed S. Shaheen ${ }^{1}$, Hamdy A. Shaaban ${ }^{1}$, Ahmed M.S. Hussein ${ }^{2, *}$, Mohamed B.M. Ahmed ${ }^{3}$, \\ Khaled El-Massry ${ }^{4,1}$, Ahmed El-Ghorab ${ }^{4,1}$ \\ ${ }^{1}$ Flavor and Aroma Department, \\ ${ }^{2}$ Food Science \& Technology Department, \\ ${ }^{3}$ Food Toxicology \& Contaminants Department, National Research Centre, Egypt \\ ${ }^{4}$ Faculty of Science, Chemistry Department, Aljouf University; Kingdom Saudi Arabia,
}

Key words: chitosan/fructose system, antioxidant activity, antimicrobial activity, fresh minced beef meat

In the present study the effect of chitosan/fructose Maillard reaction products (CF-MRPs) as antioxidant and antimicrobial agents was evaluated and applied on minced beef meat during frozen storage. Antioxidant and antimicrobial properties of chitosan-fructose complexes were tested. Antioxidant properties were measured by the DPPH, $\beta$-carotene and ABTS methods. These three methods showed the same profile of antioxidant activity. Chitosan with $4 \%$ fructose autoclaved for $45 \mathrm{~min}$ (CF9) showed to have the most effective antioxidant activity. It was demonstrated that the browning product exhibited antioxidant activity. For antimicrobial activity, most chitosan-fructose complexes were less effective than chitosan. Thus, MRPs derived from chitosan-sugar model system can be promoted as a novel antioxidant to prevent lipid oxidation in minced beef. Chitosan-sugar complex could be a potential alternative natural product for synthetic food additive replacement that would additionally meet consumer safety requirement.

\section{INTRODUCTION}

The Maillard reaction occurring between amino group and carbonyl group produces neo-formed compounds having certain levels of antioxidant activity depending on the reaction conditions and the type of reactants. The meat products have low oxidative stability and are very susceptible to rancidity during production and storage as any proteinaceous foods. Microbial activity is generally responsible for the deteriorations in meats and meat products accompanied with biochemical and enzymatic alterations [Devlieghere et al., 2004]. Applying antimicrobial agents either by dipping or spraying on the surface of the product is one of many traditional ways to control microbial spoilage and improve food products [Kerry et al., 2006].

Quintavalla \& Vicini [2002] reported that activity of the antimicrobial stuffs is limited due to uncontrolled passage into the food matrix and partial inactivation of the active compounds due to interaction with food components. Many reports have pointed to lipid oxidation in meat and meat products which may be regulated by using different antioxidants [Nissen et al., 2004]. The quality of meat and meat products were improved by adding some natural antioxidant compounds as chitosan and its derivatives [Ouattara et al., 2000; Darmadji \& Izumimoto, 1994;

\footnotetext{
* Corresponding Author: E-mail: a_said22220@yahoo.com of antioxidants against free radicals like 1,1-diphenyl-2-pic-

Jo et al., 2001]. Numerous studies reported the antimicrobial efficacy of chitosan against a variety of spoilage and pathogenic organisms in meat and meat products [Roller et al., 2002; Soultos et al., 2008]. Prashanth \& Tharanathan [2007] reported that chitosan has some characters, such as being non-toxic, biodegradable and biocompatible which make chitosan have a broad range of application in many areas. Also, it has exhibited some antimicrobial and antioxidative properties, so it is used as a food preservative and has been shown to have a broad-spectrum of antimicrobial activities against gram-positive and gram-negative bacteria and fungi [Prashanth \& Tharanathan, 2007]. The most widely used synthetic antioxidants as butylated hydroxyanisole (BHA), butylated hydroxytoulene (BHT), propyl gallate (PG) and tertiary butylhydroquinone (TBHQ), and metal chelating agents can be added to food products to avoid or delay autoxidation process [Kamil et al., 2002]. However, the growing consumer demand for food devoid of synthetic antioxidants has focused research on the development of new natural preservatives [Matsugo et al., 1998]. Several sources of natural antioxidants are known [Shahidi, 1997], and some of them, such as those of rosemary and sage, are currently used in a variety of food products.

Different antioxidant activity methods have been used to monitor and compare the antioxidant activity of foods. Some analytical methods measure the radical scavenging activity 
rylhydrazyl (DPPH) [Phisut \& Jiraporn, 2013], others determining the resistance of lipid or lipid emulsions to oxidation in the presence of the antioxidant being tested as the thiobarbituric acid-reactive substances (TBRS) and also, methods using free radical traps as the ABTS [2,2-azinobis(3-ethylbenzothiazoline-6-sulfonic acid)] radical cation [Thaipong et al., 2006].

The Maillard reaction products (MRPs) produced in an amino acid-sugar model system have been known to be accompanied with the formation of neo-formed and desirable compounds with prominent antioxidant activity [Jayathilakan \& Sharma, 2006]. Chitosan has amino groups which can react easily with the carbonyl group of reducing sugar (glucose, fructose, maltose and lactose) leading to MRPs formation [Phisut \& Jiraporn, 2013].

Chang et al. [2011] indicated that MRPs which were produced by autoclaving $\left(121^{\circ} \mathrm{C}\right)$ chitosan $(1 \%)$ and glucose $(1.0 \%, 1.5 \%$, or $2.0 \%)$ for $15 \mathrm{~min}$, had significantly higher antioxidative activity when compared with chitosan or glucose alone. Glucosamine derivative derived from chitosan/glucose model system has been reported to have a relatively higher antibacterial activity against Escherichia coli and Staphylococcus aureus, when compared with chitosan [Chang et al., 2008].

The main objective of our research was to determine the potential of MRPs of chitosan/ fructose model system as an antioxidant and antibacterial agent to prevent the deterioration of meat and meat products via lipid oxidation and food borne microorganisms. To reach the target, our work aimed to: (1) evaluate the antioxidative and antimicrobial properties of the chitosan-fructose Maillard reaction products, with various levels of fructose $(1 \%, 2 \%$, or $4 \%$ ), and (2) evaluate its preservative effect on fresh minced beef meat during chill storage.

\section{MATERIALS AND METHODS}

\section{Materials}

Chitosan was obtained in a powder form (Fluka, Germany). It had a deacetylation degree of $96 \%$ and the moisture content below 10\%. Tert-butyl hydroquinone (TBHQ), 2,2-diphenyl-1-picrylhydrazyl (DPPH), $\beta$-Carotene, linolenic acid, Tween-20 (polyoxyethylene sorbitan monopalmitate), chloroform, acetic acid and 2,2-azino-bis(3-ethylbenzthiazoline-6-sulfonic acid) (ABTS ${ }^{*}$ ) were purchased from Aldrich-Sigma Chemical Co. (Sigma-Aldrich GmbH, Sternheim, Germany). Fresh beef meat was obtained from local market.

\section{Preparation of chitosan-fructose Maillard reaction products (CF-MRPs)}

One gram of chitosan (96\% degree of deacetylation); was dissolved in $100 \mathrm{~mL}$ of acetic acid (1\%, Merck) in which $1.0 \%, 2 \%$, or $4.0 \%$ fructose (Merck) were added. The $\mathrm{pH}$ value of each solution was adjusted to 6.0 by adding $1 \mathrm{~N} \mathrm{NaOH}$. After being autoclaved at $140 \pm 1^{\circ} \mathrm{C}$, for 15,30 and $45 \mathrm{~min}$ and cooled, the CF-MRP solutions with fructose levels of $1 \%$, $2 \%$, or $4 \%$ were assigned codes of CF1 to CF9, and chitosan only was assigned code of $\mathrm{C}$, respectively. The samples were assigned the following keys, CF1: chitosan+fructose $1 \%$ at $15 \mathrm{~min}$; CF2: chitosan+fructose $1 \%$ at $30 \mathrm{~min}$; CF3: chitosan+fructose $1 \%$ at $45 \mathrm{~min}$; CF4: chitosan+fructose $2 \%$ at $15 \mathrm{~min}$; CF5: chitosan + fructose $2 \%$ at 30 mins; CF6: chitosan + fructose $2 \%$ at $45 \mathrm{~min}$; CF7: chitosan + fructose $4 \%$ at $15 \mathrm{~min}, \mathrm{CF} 8$ : chitosan+fructose $4 \%$ at $30 \mathrm{~min}$; and CF9: chitosan + fructose $4 \%$ at $45 \mathrm{~min}$.

\section{Fourier-Transform-Infra Red spectroscopy analysis}

Chitosan-fructose complex formation was lyophilized then evaluated using Fourier Transform Infrared Spectroscopy (Shimadzu, Japan). The obtained spectral peaks were recorded between wave numbers of $400-4000 \mathrm{~cm}^{-1}$.

\section{Determination of antioxidant activity}

\section{DPPH radical-scavenging method}

The DPPH radical-scavenging activity of the test samples was estimated by the method of Yamaguchi et al. [1998]. The diluted sample $(200 \mu \mathrm{L})$ was mixed with $800 \mu \mathrm{L}$ of tris-HCl buffer (100 mmol/L, pH 7.4), then $1 \mathrm{~mL}$ of $500 \mathrm{mmol} / \mathrm{L}$ $\mathrm{DPPH}$ - in methanol was added and the mixture was vortexed. The absorbance was measured at $517 \mathrm{~nm}$ using a spectrophotometer (model UV-1601PC, Shimadzu Co., Tokyo, Japan), after 30 min of incubation in the dark. Inhibition \% was calculated as:

$$
\text { Inhibition } \%=\left[\left(\mathrm{Abs}_{\text {control }}-\mathrm{Abs} \text { sample }\right) / \mathrm{Abs}_{\text {control }}\right] \times 100
$$

\section{$\beta$-Carotene radical-scavenging activity method}

The antioxidant activity of CF-MRPs was evaluated acc. to Jayaprakasha et al. [2001] with some modifications. $0.1 \mathrm{mg}$ of $\beta$-carotene in $0.2 \mathrm{~mL}$ of chloroform, $10 \mathrm{mg}$ of linoleic acid and $100 \mathrm{mg}$ of Tween-20 (polyoxyethylene sorbitan monopalmitate) were mixed. The solvent was evaporated under vacuum at $40^{\circ} \mathrm{C}$ and the resulting mixture was diluted with $10 \mathrm{~mL}$ of water and was mixed well. To this mixture, $20 \mathrm{~mL}$ of oxygenated water were added. Four milliliter aliquots mixtures were pipetted into different test tubes containing $1 \mathrm{~mL}$ of CF-MRPs. Control $(0.2 \mathrm{~mL}$ of ethanol was added to $4 \mathrm{~mL}$ of the above emulsion) and blank (mixture without $\beta$-carotene) tubes were also prepared. All tubes were placed in a water bath $\left(50^{\circ} \mathrm{C}\right)$. The absorbance was measured at $470 \mathrm{~nm}$ (zero time $(\mathrm{t}=0), \mathrm{t}=60 \mathrm{~min}$ and 15 min intervals) until the color of $\beta$-carotene vanished in the control tubes. All determinations were carried out in triplicates and the antioxidant activity (AA) of CF-MRPs were evaluated in terms of bleaching of the $\beta$-carotene using the following formula,

$$
\text { Inhibition\% }=\left[\left(\mathrm{A}_{B}-\mathrm{A}_{A}\right) / \mathrm{A}_{B}\right] \times 100
$$

where: $A_{B}$ : absorption of blank sample $(t=0 \mathrm{~min})$ and $A_{A}$ absorption of sample solution ( $\mathrm{t}=60 \mathrm{~min})$.

\section{ABTS radical cation decolorization assay}

The spectrophotometric analysis of ABTS' radical scavenging activity of tested chitosan solutions were determined according to the method described by Chien et al. [2007]. 
The ABTS radical cation was produced by the reaction between $7 \mathrm{mmol} / \mathrm{L} \mathrm{ABTS}^{\cdot}$ in $\mathrm{H}_{2} \mathrm{O}$ and $2.45 \mathrm{mmol} / \mathrm{L}$ potassium persulfate, stored in the dark at room temperature for 12 h. Before usage, the ABTS solution was diluted to get an absorbance of $0.7 \pm .025$ at $734 \mathrm{~nm}$ with phosphate buffer $(0.1 \mathrm{~mol} / \mathrm{L}, \mathrm{pH}$ 7.4). Then, $2 \mathrm{~mL}$ of ABTS solution was added to $1 \mathrm{~mol} / \mathrm{L}$ of CF-MRPs. The reaction mixture was allowed to stand at room temperature for $6 \mathrm{~min}$, and the absorbance was immediately recorded at $734 \mathrm{~nm}$ using UV-spectrophotometer. A standard curve was obtained by using Trolox standard $(0.25-1 \mathrm{mmol} / \mathrm{L})$ in ethanol. The absorbance of the resulting oxidized solution was compared as mmol/L Trolox equivalents (TE).

\section{Thiobarbituric acid-reactive substances (TBARS)}

Fresh local beef meat, which was divided to small particles $\left(1 \mathrm{~cm}^{3}\right)$ and dipped in the CF1 to CF9, and C solutions for $10 \mathrm{~min}$. Samples without any dipping treatment and samples dipped in deionized water for 10 min were assigned codes of CON and DW, respectively. After dipping, the samples were placed in plastic bags, and stored at $4^{\circ} \mathrm{C}$ for 7 days. The TBARS values of the samples were determined according to the methods described by Liu et al. [2009]. Malondialdehyde (MDA) and other aldehydes, formed during lipid oxidation in the beef meat were measured, and reported as TBARS values in units of MDA equivalent $/ \mathrm{kg}$ beef meat samples. The amount of the pink-colored TBA complex was measured with a spectrophotometer at $510 \mathrm{~nm}$. Triplicate samples were analyzed.

\section{Antimicrobial activity assay}

Pure cultures of the bacteria (Staphylococcus aureus, Pseudomonas aeruginosa, Salmonella paratyph and Escherichia coli) and fungi (Aspergillus niger, Aspergillus parasiticus, and Candida albicans) were provided by the Department of Microbiology, National Research Centre (NRC) (Dokki, Giza, Egypt). The antimicrobial activity was determined by measuring the diameter of inhibition zone [Bauer et al., 1996].

\section{Determination of Minimum Inhibitory Concentration (MIC)}

The MIC is defined as the minimum level of a sample that inhibits the growth (populations) of microbial colonies by $90 \%$. The MIC was determined by the serial dilutions method. For the studies, chitosan solution was diluted with a sterile physiological saline $(\mathrm{pH} 7.2)$ in relation to the active substance. In order to establish MIC values, chitosan solutions in the ranges from 0.1 to $2.5 \mathrm{mg} / \mathrm{mL}$ (the concentration increasing by $0.1 \mathrm{mg} / \mathrm{mL}$ ) were prepared. One $\mathrm{mL}$ of the breeding-ground was poured into the test tubes, and then $0.5 \mathrm{~mL}$ of the investigated preparation was added. Subsequently, $0.5 \mathrm{~mL}$ of given microorganisms culture was added to the test tubes. In the case of $C$. albicans and all the bacterial strains, cultures were diluted 1:1000. Each time, a sample controlling the growth of investigated microorganisms was made. Cultures of all the bacteria and $C$. albicans were incubated at $37^{\circ} \mathrm{C}$ for $24 \mathrm{~h}$, while other mycotic strains were incubated at $25^{\circ} \mathrm{C}$ for 7 days.

\section{RESULTS AND DISCUSSION}

\section{FT-IR spectra analyses of chitosan-fructose Maillard reaction products (CF- MRPs)}

FT-IR spectroscopy has been used to determine the structure of chitin and chitosan [Kurita, 1986]. Figure 1 showed the FT-IR spectra of chitosan, fructose and CF-MRPs. Chitosan-fructose complexes were evaluated by FT-IR analysis, spectra of the reacted chitosan-fructose systems were compared with the corresponding spectrum of both purified fructose and chitosan. Figure 1 showed the data obtained for fructose, chitosan and chitosan with 1,2 , and $4 \%$ of fructose autoclaved for 15,30 and $45 \mathrm{~min}$ at $140 \pm 1{ }^{\circ} \mathrm{C}$. The characteristic absorption bands at 3460-3411, 3366-3336 and 2942-2929 $\mathrm{cm}^{-1}$ are corresponding to $\mathrm{OH}, \mathrm{NH}$ and $\mathrm{CH}$ stretching regions of chitosan were observed in all samples. CF-MRPs showed a decrease of the band at $1573 \mathrm{~cm}^{-1}$ corresponding to primary amine groups [Chang et al., 2008] and indicating the successful interaction between the carbonyl group of the fructose (reducing sugar) and the amine group of chitosan.

On the other hand, the $1620-1640 \mathrm{~cm}^{-1}$ band showed a sharp increase due to the appearance of a new band corresponding to $\mathrm{C}=\mathrm{N}$ linkage indicating the formation of Schiff base during the interaction between fructose and chitosan [Umemura \& Kawai, 2007]. Our results showed also intense browning indices. Data obtained from chitosan-fructose systems indicated the successful cleavage of fructose with chitosan chains during storage.

It is well-known that the Maillard reaction is mainly divided into three stages. The initial reaction between sugar-amino compound forming Amadori product through the Schiff base, then the latter is broken into numerous compounds. Finally, these products condense with amino compounds forming brown polymers (melanoidins) [Martins et al., 2001]. From FT-IR spectral data, it is suggested that the amino group of chitosan covalently attached to fructose forming a glycated product. This glycated product or Schiff base, rearranges to a more stable ketoamine or Amadori product. The Amadori products can then form cross-links with other amino groups resulting in polymeric aggregates named advanced glycation end-products [Friedman, 1966].

\section{Antioxidant activity assays}

\section{DPPH radical-scavenging activity}

The DPPH stable radical is used for the determination of primary antioxidant activity of fruits, vegetables, aromatic and medicinal plants and also MRPs in vitro. The DPPH radical is scavenged by antioxidants through the hydrogen donation to form a stable DPPH-H molecule, measured as a decrease of DPPH absorbance at $517 \mathrm{~nm}$ (purple to yellow) [Wong et al., 2006].

Results in Table 1 showed the DPPH radical-scavenging activity of the different CF-MRPs, compared with that of TBHQ. The CF9 showed the strongest ability to scavenge DPPH radicals followed by the CF8, CF5 and CF3. On the other hand, both chitosan and fructose exhibited weak ability to scavenge the DPPH radicals (5 and 3\%, respectively), depending on their concentration. 

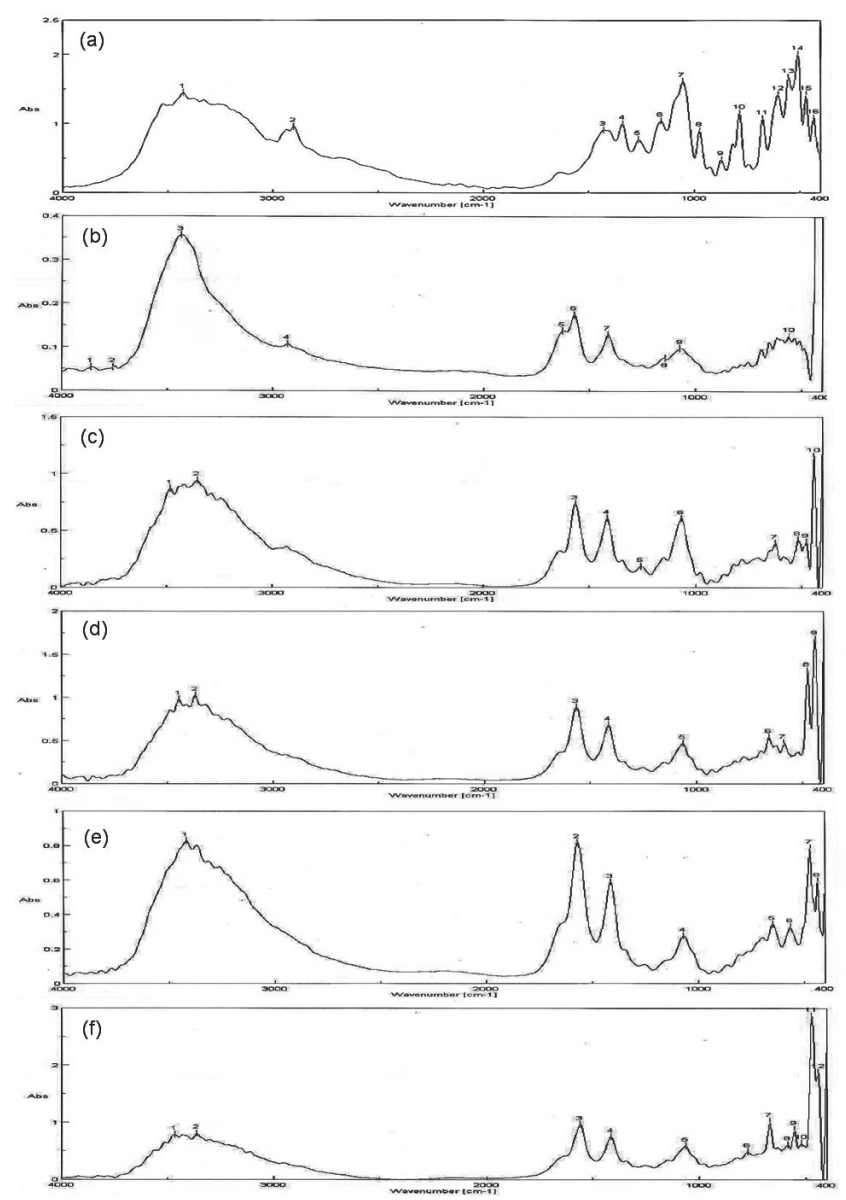
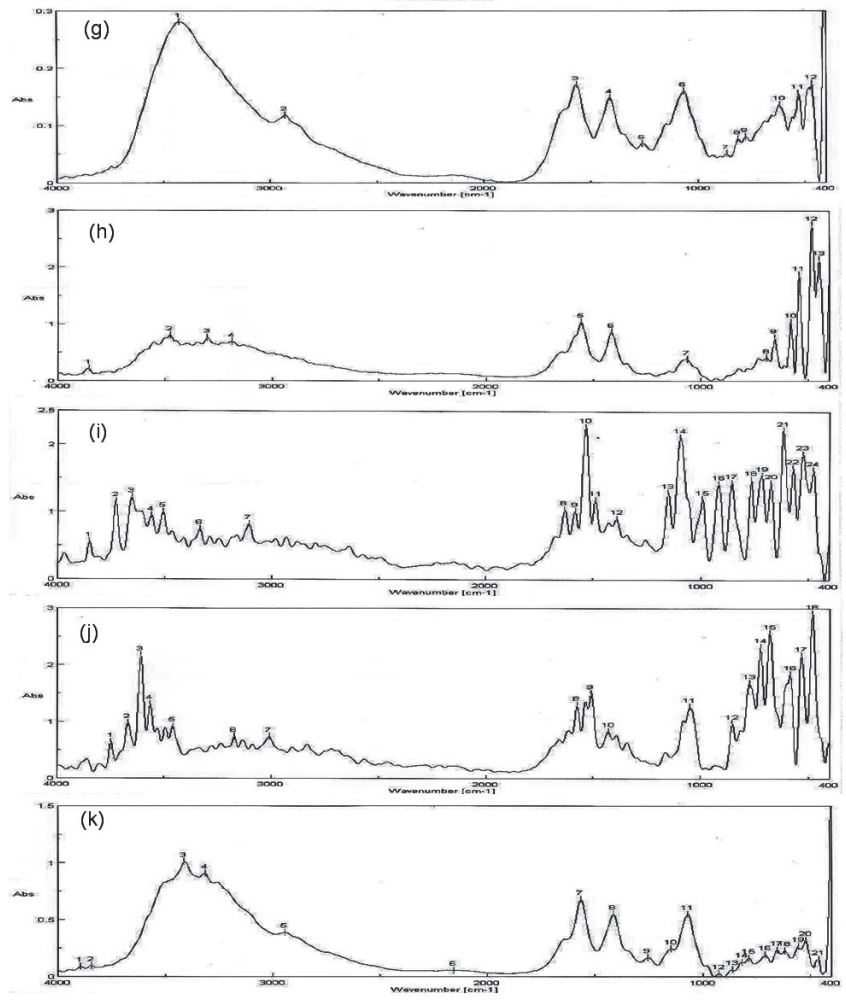

FIGURE 1. FT-IR spectral bands of: (a) fructose, (b) chitosan, and (c) to (k) chitosan-ftuctose complexes (from CF1 to CF9, respectively).

This result indicated that MRPs derived from the chitosan-fructose model system were free radical inhibitors, which can work as the primary antioxidant. The present results were in agreement with previous observations reported by Kanatt et al. [2007] who stated that the glucose/chitosan complexes had high antioxidant activity in comparison with chitosan or glucose alone.

Literature revealed that the chitosan-sugar MRPs exhibited significantly higher DPPH scavenging activities when compared to chitosan and sugar alone [Kanatt et al., 2008; Chang et al., 2011] and the scavenging activity increased by increasing the concentration of sugar used (reaching the plateau at $30 \mathrm{mg} / \mathrm{mL}$ ribose) [Sumaya-Martinez et al., 2005]. Caramelization reaction that may occur during heating of chitosan-sugar model system contributes to its antioxidant activity [Phisut \& Jiraporn, 2013].

\section{$\beta$-Carotene radical-scavenging activity $(B C)$}

Peroxyl free radicals produced from linoleic acid oxidation oxidize the highly unsaturated $\beta$-carotene and the presence of antioxidants will minimize that in $\beta$-carotene/linoleic acid assay. $\beta$-Carotene bleaching inhibition effects of different CF-MRPs are shown in Table 1. The results showed that there were significant differences in the radical scavenging activities of the different CF-MRPs prepared with various levels of fructose autoclaved at different times (15, 30 and $45 \mathrm{~min}$ ).
CF9 (high fructose content at $140^{\circ} \mathrm{C}$ for 45 min, model system) exhibited the highest antioxidant activity among other model systems (38.9\%). This result could be attributed to some brown complexes of the Maillard reaction formed during thermal interaction between fructose and chitosan. According to our knowledge, there are no studies carried out on $\beta$-carotene free radical scavenging activity of chitosan/ sugar Maillard reaction products.

\section{ABTS radical-scavenging activity}

ABTS assay is more practical than that of DPPH and $\beta$-carotene-linoleate assay [Miller, 1996]. When an antioxidant is added to the radicals, there is a degree of decolorization and reversing the formation of the DPPH radical and $\mathrm{ABTS}^{\bullet}+$ cation as:

$$
\mathrm{ABTS}^{\bullet+}+\mathrm{AH} \rightarrow \mathrm{ABTS}^{+}+\mathrm{A} .
$$

The results gained using $\mathrm{K}_{2} \mathrm{~S}_{2} \mathrm{O}_{8}$ as an oxidant show that the presence of peroxodisulfate increases the rate of $\mathrm{ABTS}^{\cdot+}$ autobleaching in a concentration-dependent manner. ABTS ${ }^{++}$ radicals were generated in the $\mathrm{ABTS} / \mathrm{K}_{2} \mathrm{~S}_{2} \mathrm{O}_{8}$ system [Kaviarasan et al., 2007]. The results in Table 1 showed that there were significant differences in the ABTS radical-scavenging activities of the CF-MRPs as obtained in the DPPH and $\beta$-carotene assay. The activities of the CF-MRPs scavenging the ABTS radicals were in the descending order: $\mathrm{CF} 9>\mathrm{CF} 8>\mathrm{CF} 6>$ 
CF3 $>$ CF7 $>$ CF5 $>$ CF4 $>$ CF2 $>\mathrm{CF} 1$ and their activity values were $0.294,0.192,0.185,0.172,0.128,0.125,0.095$, 0.08 and $0.0038 \mathrm{mmol} / \mathrm{L}$ Trolox Equiv., respectively.

\section{Lipid oxidation (TBARS values)}

Concentrations of MDA in the lipid fraction of the minced beef meat during the four-week storage period are presented in Table 2. MDA values were significantly $(\mathrm{P} \leq 0.05)$ different in all treatments during the whole storage period. CF9 treatments $(1 \%, 2 \%$ and $4 \% \mathrm{v} / \mathrm{w})$ exhibited the lowest MDA values for all measured samples. CF9 (4\%) has exhibited the best antioxidative effect $(\mathrm{P} \leq 0.05) \quad(710 \mu \mathrm{g} / \mathrm{kg} \mathrm{MDA})$ at the end of storage period and this result could be ascribed to the occurrence of CF-MRPs which induce a synergistic effect preventing the lipid oxidation. Our results are in agreement with findings of Darmadji \& Izumimoto [1994] who reported that the TBA value (expressed as mg MDA/ $\mathrm{kg}$ ) of beef containing $1 \%$ chitosan was at the same level after 10 days of storage at $4^{\circ} \mathrm{C}$. Furthermore, Chang et al. [2011] revealed a significant decrease of TBARS values $(\mathrm{P}<0.05)$ during storage for five or more days under refrigeration of samples dipped in the chitosan-glucose-MRPs solutions.

In addition, CF-MRPS antioxidant activity could be ascribed to the results of Shahidi et al. [1999] who explained that chitosan derivatives chelate the free iron, which are released from hemoproteins during heat processing or storage and thus inhibit the lipid oxidation of products.

\section{Antimicrobial activity assay}

The results of antibacterial and antifungal activities of chitosan solutions in terms of Minimal Inhibitory Concentration (MIC) are presented in Table 3. All bacteria and fungi, which have been used in these studies, were susceptible to chitosan. The results of antibacterial and antifungal activities of chitosan after treated by CF-MRPs are presented in the Table 4. All treatments showed very low effect against all tested microorganisms. Chemically-modified chitins including partially deacetylated and carboxymethlyated chitins were found to have potent immunological and antibacterial activities [Nishimura et al., 1984; Ryan et al., 2001].

The protection of the host against bacterial infection is stimulated by chitosan [Iida et al., 1987]. The effectiveness of chitosan bacteriostatic properties was tested against bacterial strains and a common skin fungus. Powered chitin, chitosan or whole crab shells were not effective in any of the tests, but the solution of chitosan in acetic acid inhibited the bacterial and fungal strains [Cheng \& Li, 2000].

The antimicrobial activity of chitosan-sugar complexes was proposed by several mechanisms. The inhibition of microbial growth is referred to the availability of an amino group (cation charged groups) on chitosan that interacts with $\mathrm{N}$-acetylmuramic acid, sialic acid and neuraminic acid (anionic components), on the microbial cell membrane, results in changes in its permeability for essential nutrients and in inhibiting some enzymes [Mahae et al., 2011].

Chitosan possesses high chelating capacity for various metal ions (including $\mathrm{Ni}^{2+}, \mathrm{Zn}^{2+}, \mathrm{Co}^{2+}, \mathrm{Fe}^{2+}, \mathrm{Mg}^{2+}$, and $\mathrm{Cu}^{2+}$ ) in acid conditions, and it has been widely applied for the removal or recovery of metals in different industries. Metal ions
TABLE 1. Antioxidant activity of chitosan-fructose model systems by DPPH, BC and ABTS scavenging assays.

\begin{tabular}{lcccc}
\hline C-F MRPs & DPPH (I\%) & BC (I \%) & $\begin{array}{c}\text { ABTS (Trolox } \\
\text { Eq. mmol/L) }\end{array}$ \\
\hline CF1 & $12.4 \pm 0.28$ & $11.4 \pm 0.99$ & $0.0038 \pm 0.00$ \\
CF2 & $15.8 \pm 0.15$ & $15.2 \pm 1.7$ & $0.08 \pm 0.001$ \\
CF3 & $22.8 \pm 2.1$ & $26.3 \pm 2.3$ & $0.172 \pm 0.008$ \\
CF4 & $16.7 \pm 1.8$ & $15.7 \pm 1.2$ & $0.095 \pm 0.001$ \\
CF5 & $23.7 \pm 2.3$ & $20.4 \pm 1.8$ & $0.125 \pm 0.008$ \\
CF6 & $4.2 \pm 0.1$ & $27.3 \pm 3.4$ & $0.185 \pm 0.003$ \\
CF7 & $23 \pm 2.6$ & $23.9 \pm 2.0$ & $0.128 \pm 0.007$ \\
CF8 & $29.5 \pm 3.1$ & $29.7 \pm 2.4$ & $0.192 \pm 0.01$ \\
CF9 & $37.8 \pm 3.2$ & $38.9 \pm 2.8$ & $0.294 \pm 0.06$ \\
\hline
\end{tabular}

CF-MRPs: chitosan/fructose Maillard reaction products, CF1: chitosan + fructose $1 \%$ at $15 \mathrm{~min}$; $\mathrm{CF} 2$ : chitosan + fructose $1 \%$ at $30 \mathrm{~min}$; $\mathrm{CF} 3$ : chitosan + fructose $1 \%$ at $45 \mathrm{~min}$; CF4: chitosan + fructose $2 \%$ at $15 \mathrm{~min}$; CF5: chitosan + fructose $2 \%$ at $30 \mathrm{~min}$; CF6: chitosan + fructose $2 \%$ at $45 \mathrm{~min}$; CF7: chitosan + fructose $4 \%$ at $15 \mathrm{~min}$, CF8: chitosan + fructose $4 \%$ at 30min; CF9: chitosan +fructose $4 \%$ at $45 \mathrm{~min}$, I\% :Inhibition percentage.

TABLE 2. Thiobarbituric acid-reactive substances (TBARS) of CF9 (1\%, $2 \%$ and $4 \%$ ) during frozen storage of the fresh minced beef meat.

\begin{tabular}{l|c|c|c|c}
\hline \multirow{2}{*}{ Treatments } & \multicolumn{4}{|c}{ TBARS (MDA $\mu \mathrm{g} / \mathrm{kg})$} \\
\cline { 2 - 5 } & 1 week & 2 week & 3 week & 4 week \\
\hline $\mathrm{C}$ & 607.3 & 1350 & 2843 & 3420 \\
$\mathrm{MBM}+1 \%$ CF9 & 462 & 852 & 1215 & 1589 \\
$\mathrm{MBM}+2 \%$ CF9 & 342 & 523 & 729 & 1123 \\
MBM +4\% CF9 & 235 & 345 & 523 & 710 \\
\hline
\end{tabular}

C: control minced beef meat; MBM: minced beef meat and CF9: chitosan/fructose MRPs at 1,2 and $4 \%$ fructose.

TABLE 3. Antibacterial and antifungal activity of chitosan.

\begin{tabular}{lc|c}
\hline Microorganism & Inhibition zone (mm) & MIC (mg/mL) \\
\hline Escherichia coli & 17 & 1.5 \\
Pseudomonas aeruginosa & 14 & 1.9 \\
Staphylococcus aureus & 18 & 0.8 \\
Salmonella paratyphi & 12 & 2.0 \\
Candida albicans & 19 & 0.7 \\
Aspergillus niger & 10 & 2.3 \\
Aspergillus parasiticus & 15 & 1.8 \\
\hline
\end{tabular}

MIC: minimum inhibitory concentration.

that combine with the cell wall molecules of microorganisms are crucial for stability of the cell wall. Chitosan-mediated chelation of such metal ions has often been implicated in antimicrobial action [Kurita, 1998].

The inhibition of Candida tropicalis growth by chitosan-fructose CF9 MRPs, is in agreement with findings obtained by Allan \& Hardwiger [1984] who stated that the solution of chitosan (1\%) with acetic acid had completely inhibited the growth of Candida tropicalis. 
TABLE 4. Antibacterial and antifungal activity of CF- MRPs.

\begin{tabular}{|c|c|c|c|c|c|c|c|}
\hline \multirow{2}{*}{ Sample } & \multicolumn{7}{|c|}{ Microorganism/Inhibition zone (mm) } \\
\hline & E. coli & $\begin{array}{c}\text { Salmonella } \\
\text { paratyphi }\end{array}$ & $\begin{array}{l}\text { Candida } \\
\text { albicans }\end{array}$ & $\begin{array}{c}\text { Pseudomonas } \\
\text { aeruginosa }\end{array}$ & $\begin{array}{c}\text { Staphylococcus } \\
\text { aurus }\end{array}$ & Aspergillus niger & $\begin{array}{l}\text { Aspergillus } \\
\text { parasiticus }\end{array}$ \\
\hline CF1 & + & + & +++ & + & ND & + & ++ \\
\hline CF2 & + & ++ & + & ND & ND & ND & ND \\
\hline CF3 & ND & ++ & ++ & + & ++ & + & + \\
\hline CF4 & ND & ++ & + & ND & + & ND & + \\
\hline CF5 & ND & + & + & ND & ND & ND & ND \\
\hline CF6 & + & ++ & + & ++ & + & + & + \\
\hline CF7 & ND & ++ & ++ & + & + & + & + \\
\hline CF8 & ND & ++ & + & + & + & ND & + \\
\hline CF9 & + & + & + & + & ND & ND & + \\
\hline
\end{tabular}

(ND): Negative, (+): $1 \mathrm{~mm},(++): 2 \mathrm{~mm},(+++): 3 \mathrm{~mm}$.

TABLE 5. Statistical analysis of sensory properties of minced beef meat treated with C-F MRPs.

\begin{tabular}{lcccccc}
\hline Samples & Taste (10) & Odor (10) & Color (10) & Mouth feel (10) & Appearance (10) \\
\hline MBM with CF1 & $6.2^{\mathrm{b}} \pm 0.74$ & $7.7^{\mathrm{a}} \pm 0.25$ & $8.2 \pm 0.79$ & $8.4 \pm 1.17$ & $8.7 \pm 0.82$ \\
MBM with CF2 & $5.8^{\mathrm{b}} \pm 0.49$ & $7.4^{\mathrm{a}} \pm 0.33$ & $8.0 \pm 0.94$ & $7.9 \pm 0.99$ & $8.0 \pm 0.94$ \\
MBM with CF3 & $7.6^{\mathrm{a}} \pm 0.37$ & $8.1^{\mathrm{a}} \pm 0.66$ & $8.7 \pm 0.82$ & $8.5 \pm 0.53$ & $8.8 \pm 0.79$ \\
MBM with CF4 & $6.0^{\mathrm{b} \pm 0.42}$ & $6.5^{\mathrm{b}} \pm 0.21$ & $8.0 \pm 1.05$ & $7.6 \pm 0.52$ & $8.0 \pm 1.05$ \\
MBM with CF5 & $5.5^{\mathrm{c}} \pm 0.95$ & $6.3^{\mathrm{b}} \pm 0.13$ & $7.5 \pm 0.84$ & $7.9 \pm 0.56$ & $7.5 \pm 0.84$ \\
MBM with CF6 & $7.2^{\mathrm{a}} \pm 0.92$ & $8.3^{\mathrm{a}} \pm 0.16$ & $8.5 \pm 0.71$ & $8.4 \pm 1.26$ & $8.5 \pm 0.71$ \\
MBM with CF7 & $7.8^{\mathrm{a}} \pm 0.48$ & $5.8^{\mathrm{c}} \pm 0.35$ & $8.1 \pm 0.99$ & $7.9 \pm 0.99$ & $8.6 \pm 0.84$ \\
MBM with CF8 & $8.2^{\mathrm{a}} \pm 0.40$ & $7.2^{\mathrm{a}} \pm 0.96$ & $8.6 \pm 1.26$ & $8.0 \pm 1.05$ & $8.6 \pm 1.26$ \\
MBM with CF9 & $7.8^{\mathrm{a}} \pm 0.44$ & $8.0^{\mathrm{a}} \pm 0.76$ & $8.6 \pm 0.84$ & $8.2 \pm 1.23$ & $8.6 \pm 0.99$ \\
\hline LSD at.05\% & 0.941 & 1.02 & $\mathrm{NS}$ & $\mathrm{NS}$ & NS \\
\hline
\end{tabular}

$\mathrm{CF} 1$ : chitosan + fructose $1 \%$ at $15 \mathrm{~min} ; \mathrm{CF} 2$ : chitosan + fructose $1 \%$ at $30 \mathrm{~min} ; \mathrm{CF} 3$ : chitosan + fructose $1 \%$ at $45 \mathrm{~min}$; $\mathrm{CF} 4$ : chitosan + fructose $2 \%$ at $15 \mathrm{~min}$; CF5: chitosan + fructose $2 \%$ at $30 \mathrm{~min}$; CF6: chitosan + fructose $2 \%$ at $45 \mathrm{~min}$; CF7: chitosan + fructose $4 \%$ at $15 \mathrm{~min}$, CF 8 : chitosan + fructose $4 \%$ at $30 \mathrm{~min}$; CF9: chitosan + fructose $4 \%$ at $45 \mathrm{~min}$.

TABLE 6. Statistical analysis of sensory properties of minced beef meat treated with C-F MRPs after two-weak storage.

\begin{tabular}{lccccccc}
\hline Samples & Taste (10) & Odor (10) & Color (10) & Mouth feel (10) & Appearance (10) \\
\hline C & $7.60^{\mathrm{b}} \pm 0.09$ & $8.20^{\mathrm{b}} \pm 0.15$ & $6.80^{\mathrm{b}} \pm 0.13$ & $6.20^{\mathrm{b}} \pm 0.2$ & $6.30^{\mathrm{b}} \pm 0.09$ \\
MBM+1\% CF & $9.30^{\mathrm{a}} \pm 0.11$ & $9.80^{\mathrm{a}} \pm 0.12$ & $8.00^{\mathrm{a}} \pm 0.19$ & $7.80^{\mathrm{a}} \pm .16$ & $8.90^{\mathrm{a}} \pm 0.13$ \\
MBM +2\% CF & $9.10^{\mathrm{a}} \pm 0.13$ & $9.50^{\mathrm{a}} \pm 0.17$ & $8.20^{\mathrm{a}} \pm 0.07$ & $7.20^{\mathrm{a}} \pm 0.08$ & $8.50^{\mathrm{a}} \pm 0.21$ \\
MBM +4\% CF & $9.25^{\mathrm{a}} \pm 0.12$ & $9.40^{\mathrm{a}} \pm 0.14$ & $8.30^{\mathrm{a}} \pm 0.08$ & $7.32^{\mathrm{a}} \pm 0.11$ & $8.70^{\mathrm{a}} \pm 0.15$ \\
\hline LSD at.05\% & 1.11 & 1.17 & 1.01 & 1.06 & 1.03 \\
\hline
\end{tabular}

C: control minced beef meat; MBM: minced beef meat and CF: chitosan-fructose MRPs at 1,2 and 4\% fructose at $45 \mathrm{~min}$.

\section{Organoleptic characteristics of the samples}

The effects of chitosan/fructose Maillard reaction products (CF-MRPs) at different levels (1,2 and 4\%) autoclaved for 15,30 and $45 \mathrm{~min}$ at $145^{\circ} \mathrm{C}$ on the organoleptic proper- ties of the minced beef meat are presented in Table 5. With increasing CF-MRPs levels, the sensory scores for the color, taste, odor, mouth feel, and appearance of the samples sharply increased. There were no significant differences between 
TABLE 7. Statistical analysis of sensory properties of minced beef meat treated with C-F MRPs after four-weak storage.

\begin{tabular}{lccccccc}
\hline Samples & Taste (10) & Odor (10) & Color (10) & Mouth feel (10) & Appearance (10) \\
\hline C & $5.00^{\mathrm{c}} \pm 0.13$ & $6.10^{\mathrm{b}} \pm 0.22$ & $4.80^{\mathrm{b}} \pm 0.11$ & $5.20^{\mathrm{b}} \pm 0.12$ & $5.10^{\mathrm{b}} \pm 0.19$ \\
MBM+1\% CF & $7.50^{\mathrm{b}} \pm 0.22$ & $7.20^{\mathrm{a}} \pm 0.18$ & $7.20^{\mathrm{a}} \pm 0.13$ & $6.30^{\mathrm{a}} \pm .11$ & $6.90^{\mathrm{a}} \pm 0.29$ \\
$\mathrm{MBM}+2 \%$ CF & $7.10^{\mathrm{b}} \pm 0.13$ & $7.10^{\mathrm{a}} \pm 0.09$ & $7.40^{\mathrm{a}} \pm 0.09$ & $6.90^{\mathrm{a}} \pm 0.14$ & $7.20^{\mathrm{a}} \pm 0.25$ \\
MBM +4\% CF & $8.05^{\mathrm{a}} \pm 0.12$ & $7.40^{\mathrm{a}} \pm 0.29$ & $7.60^{\mathrm{a}} \pm 0.15$ & $7.02^{\mathrm{a}} \pm 0.16$ & $7.50^{\mathrm{a}} \pm 0.22$ \\
\hline LSD at. $05 \%$ & 0.68 & 1.00 & 2.15 & 1.10 & 1.80 \\
\hline
\end{tabular}

C: control minced beef meat; MBM: minced beef meat and CF: chitosan-fructose MRPs at 1,2 and $4 \%$ fructose at $45 \mathrm{~min}$

the samples containing CF-MRPs at different levels with respect to color, mouth feel, and appearance tested. Also, the results showed significant differences in taste and odor between the samples treated with CF-MRPs.

\section{Organoleptic characteristics of the samples during storage for month}

Ten trained panelists were asked to detect differences between the control samples and those containing CF-MRPs at levels 1,2 and $4 \%$ for $45 \mathrm{~min}$. The mean scores from the sensory evaluation test showed that there were no significant differences ( $\mathrm{p} \geq 0.05$ ) in color, taste, odor, mouth feel, and appearance for samples treated with CF-MRPs at deferent levels (Table 6 and 7). On the other hand, significant differences were reported during storage when, color, taste, odor, mouth feel, and appearance of samples treated with CF-MRPs scored higher than the control. Moreover, samples treated with CF-MRPs at levels $4 \%$ showed higher score at all concentrations. Decreased sensorial values in all characteristics were observed after 15 days or 30 days of storage $(\mathrm{p} \leq 0.05)$. Results showed that very comparable scores were recorded among the different samples for each tested sensorial attribute, suggesting that the investigated active agents could be advantageously used to control the microbial quality without affecting sensorial properties.

Physical and sensorial characteristics of samples were comparable with control samples. The use of such CF-MRPs on processed meat products, however, can act as a "hurdle" or "barriers" that act synergistically to inhibit or retard microbial growth. Being effective against the spoilage proliferation, without affecting the sensorial properties of the prepared minced beef meat, it is possible to assess that the technique could be advantageously used to prolong the shelf life.

\section{CONCLUSIONS}

MRPs derived from chitosan-fructose model were good in antioxidant and antimicrobial properties for shelf life extension of beef meat during freezing. These properties may vary with different ratios of sugar used. Among them, CF9 seemed the most effective for participating in the formation of Maillard reaction products as evidenced by the antioxidant and antimicrobial activities. On the basis of the results obtained, MRPs from chitosan-fructose with presumed antioxidant and antimicrobial properties could be a potential alternative natural product for synthetic food additive replacement and also could meet consumer safety requirement.

\section{ACKNOWLEDGEMENT}

Chemical and financial support for this research from the Flavor and Aroma Department, and Food Science and Technology Department, and Food Toxicology and Contaminants Department, National Research Centre, Cairo, Egypt, is greatly appreciated.

\section{REFERENCES}

1. Allan C.R., Hardwiger L.A., The fungicidal effect of chitosan on fungi of varying cell wall composition. Exp. Mycol., 1984, 3, 285-287.

2. Bauer A.W., Kirby W.M., Sherris J.C., Turck M., Antibiotic susceptibility testing by a standardized single disk method. Am. J. Clin. Pathol., 1966, 45, 493-496.

3. Chang X., Chen D., Jiao X., Chitosan-based aerogels with high adsorption 414 performance. J. Phys. Chem. B, 2008, 112, 7721 -7725 .

4. Chang H.L., Chen Y.C., Tan F.J., Antioxidative properties of a chitosan-glucose Maillard reaction product and its effect on pork qualities during refrigerated storage. Food Chem., 2011, 124, 589-595.

5. Cheng C., Li Y., An Aspergillus chitosanase with potential for large-scale preparation of chitosan oligosaccharides. Biotechnol. Appl. Bioch., 2000, 32, 197-203.

6. Chien P.J., Sheu F., Huang W.T., Su M.S., Effect of molecular weight of chitosans on their antioxidative activities in apple juice. Food Chem., 2007, 102, 1192-1198.

7. Chung Y.C., Kuo C.L., Chen C.C., Preparation and important functional properties of water-soluble chitosan produced through Maillard reaction. Biores. Technol., 2005, 96, 1473-1482.

8. Darmadji P., Izumimoto M., Effect of chitosan in meat preservation. Meat Sci., 1994, 38, 243-254.

9. Devlieghere F., Vermeiren L., Debevere J., New preservation technologies: Possibilities and limitations. Int. Dairy J., 2004, 14, 273-285.

10. Friedman M., Food browning and its preservation: an overview. J. Agri. Food Chem., 1966, 44, 631- 653.

11. Iida J., Une T., Ishihara S., Tokura N., Mitzukoshi N., Azuma I., Stimulation of non-specific host resistance against Sendai virus and Escherichia coli infections by chitin derivatives in mice. Vaccine, 1987, 5, 270-274.

12. Jayaprakasha G.K., Singh R.P., Sakariah K.K., Antioxidant activity of grape seed (Vitis vinifera) extracts on peroxidation models in vitro. Food Chem., 2001, 73, 285-290. 
13. Jayathilakan K., Sharma G.K., Role of sugar-amino acid interaction products (MRPs) as antioxidants in a methyl linoleate model system. Food Chem., 2006, 95, 620-626.

14. Jo C., Lee J.W., Lee K.H., Byun M.W., Quality properties of pork sausage prepared with water-soluble chitosan oligomer. Meat Sci., 2001, 59, 369-375.

15. Kamil Y.V., Jeon Y.J., Shahidi F., Antioxidative activity of chitosans of different viscosity in cooked comminuted flesh of herring (Clupea harengus). Food Chem., 2002, 79, 69-77.

16. Kanatt S.R., Chander R., Sharma A., Chitosan glucose complex - a novel food preservative. Food Chem., 2008, 106, 521-528.

17. Kanatt S.R., Chander R., Sharma A., Antioxidant potential of mint (Mentha spicata L.) in radiation-processed lamb meat. Food Chem., 2007, 100, 451-458.

18. Kaviarasan S., Naik G.H., Gangabhagirathi R., Anuradha C.V., PriyadarsiniIn K.I., In vitro studies on antiradical and antioxidant activities of fenugreek (Trigonella foenum graecum) fruits. Food Chem., 2007, 103, 31-37.

19. Kerry J.P., O'Grady M.N., Hogan S.A., Past, current and potential utilization of active and passive packaging systems for meat and muscle-based products: A review. Meat Sci., 2006, 74, $113-130$.

20. Kurita K., Chemical modifications of chitin and chitosan. 1986, in: Chitin in Nature and Technology (ed. R.A.A. Muzzarelli). Elsevier, New York, pp. 287-293.

21. Kurita K., Chemistry and application of chitin and chitosan. Polymer Degrad. Stabil., 1998, 59, 117-120.

22. Liu D.C., Tsau R.., Lin Y.C., Jan S.S., Tan F.J., Effect of various levels of rosemary or Chinese mahogany on the quality of fresh chicken sausage during refrigerated storage. Food Chem., 2009, 117, 106-113.

23. Mahae N., Chalat C. and Muhamud P., Antioxidant and antimicrobial properties of chitosan-sugar complex. Int. Food Res. J., 2011, 18, 4, 1543-1551.

24. Martins S.I.F.S., Van Jongen W.M.F., van Boekel M.A.J.S., A review of Maillard reaction in food and implications to kinetic modeling. Trends Food Sci. Technol., 2001, 11, 364- 373.

25. Matsugo S., Mizuie M., Matsugo M., Ohwa R., Kitano R.H., Konishi T., Synthesis and antioxidant activity of water-soluble chitosan derivatives. Biochem. Molec. Biol. Int., 1998, 44, 939 -948 .

26. Miller D.D, Mineral, 1996, in: Food Chemistry (ed. O.R. Fennema). Marcel Dekker, New York, pp. 618-649.

27. Nishimura K., Nishimura S., Nishi N., Saiki I., Tokura S., Czuma I., Immunological activity of chitin and its derivatives. Vaccine, 1984, 2, 93-99.

28. Nissen L.R., Byrne D.V., Bertelsen G., Skibsted L.H., The antioxidative activity of plant extracts in cooked pork patties as evaluated by descriptive sensory profiling and chemical analysis. Meat Sci., 2004, 68, 485-495.
29. Ouattara B., Simard R.E., Piette G., Bégin A., Holley R.A, Inhibition of surface spoilage bacteria in processed meats by application of antimicrobial films prepared with chitosan. Int. J. Food Microbiol., 2000, 62, 139-148.

30. Phisut N., Jiraporn B., Characteristics and antioxidant activity of Maillard reaction products derived from chitosan- sugar solution. Int. Food Res. J., 2013, 20, 1077- 1085.

31. Prashanth K.V.H., Tharanathan R. N., Chitin/chitosan: modifications and their unlimited application potential - an overview. Trends Food Sci. Technol., 2007, 18, 117-131.

32. Quintavalla S., Vicini L., Antimicrobial food packaging in meat industry. Meat Sci., 2002, 62, 373-380.

33. Roller S., Sagoo S., Board R., O’Mahony T., Caplice E., Fitzgerald G., et al., Novel combinations of chitosan, carnocin and sulphite for the preservation of chilled pork sausages. Meat Sci., 2002, 62, 165-177.

34. Ryan E., Daly L., Mills K., Immunomodulators and delivery systems for vaccination by mucosal routes. Trends Biotech., 2001, 19, 293-307.

35. Sagoo S., Board R., Roller S., Chitosan inhibits growth of spoilage microorganisms in chilled pork products. Food Microbiol., 2002, 19, 175-182.

36. Shahidi F., Arachchi J.K.V., Jeaon Y.J., Food applications of chitin and chitosan. Trends Food Sci. Technol., 1999, 10, 37- 51.

37. Shahidi F., Natural Antioxidants: Chemistry, health effects and applications. 1997, American Oil Chemists' Society Press, Champaign, IL, pp. 301-307.

38. Soultos N., Tzikas Z., Abrahim A., Georgantelis D., Ambrosiadis I., Chitosan effects on quality properties of Greek style fresh pork sausages. Meat Sci., 2008, 80, 1150-1156.

39. Sumaya-Martinez M.T., Thomas S., Linard B., Binet A., Guerard F., Effect of Maillard reaction conditions on browning and antiradical activity of sugar-tuna stomach hydrolysate model system. Food Res. Int., 2005, 38, 1045-1050.

40. Thaipong K., Boonprakob U., Crosby K., Cisneros-Zevallos L., Byrne D.H., Comparison of ABTS, DPPH, FRAP, and ORAC assays for estimating antioxidant activity from guava fruit extracts. J. Food Comp. Anal., 2006, 19, 669-675.

41. Umemura K., Kawai S., Modification of chitosan by the Maillard reaction using 487 cellulose model compounds. Carbhydr. Polym., 2007, 68, 242-248.

42. Wong S.P., Leong L.P., Koh J.H.M., Antioxidant activity of aqueous extracted of selected plants. Food Chem., 2006, 99, 775-783.

43. Yamaguchi T., Takamura H., Matoba T., Terao J., HPLC method for the evaluation of the free radical-scavenging activity of foods by using 1,1-diphenyl-2-picrylhydrazyl. Biosci. Biotec. Biochem., 1998, 62, 1201-1204.

Submitted: 3 August 2014. Revised: 8 December 2014 and 29 October 2015. Accepted: 4 December 2015. Published on-line: 10 May 2016. 